\title{
Compliance with Therapeutic Regimen in Patients with Coronary Artery Disease
}

\author{
Jackson John ${ }^{1}$, Haseena T A ${ }^{2}$ \\ ${ }^{1}$ Staff Nurse, Askham Village Community, Cambridgeshare, UK
}

${ }^{2}$ Associate Proffessor \& HOD, Medical Surgical Nursing Department, SreeGokulam Nursing College, Trivandrum

\begin{abstract}
The purpose of this study was to assess the compliance with therapeutic regimen in patients with coronary artery disease (CAD) attending the cardiology outpatient department of Sree Gokulam Medical College Hospital (SGMCH).The objectives of the study were to assess the level of compliance with therapeutic regimen, to identify factors contributing to therapeutic compliance of patients with CAD and to identify association between therapeutic compliance and selected socio-demographic variables of patients with CAD, to identify the association between therapeutic compliance and selected factors influencing compliance. Methodology: Quantitative approach was used using consecutive sampling technique, 200 subjects were selected from the cardiology outpatient department of SGMCH, and data were collected using questionnaire to assess socio demographic data, level of compliance and knowledge of subjects regarding CAD. Attitude of subjects regarding CAD was assessed using attitude scale. The data were analysed using descriptive and inferential statistics. Results: The present study findings showed that $29 \%$ have good compliance with therapeutic regimen, $31.5 \%$ of the subjects have average and $39.5 \%$ of the subjects have poor compliance with therapeutic regimen. $21.5 \%$ have good knowledge, 55\% subjects have average knowledge and $23.5 \%$ have poor and regarding CAD. Majority (60.5\%) have favourable attitude towards CAD and 39.5\% of subjects have unfavourable attitude towards CAD. Most of the subjects have good financial support $91.5 \%$ from family for the treatment of CAD.74.5\% of subjects have adequate support from relatives and family members for the management of CAD.47\% subjects received advices from health care professionals. There was no significant association found between level of compliance of patients with CAD and selected socio demographic variables. There was a significant association between level of compliance of patients with $C A D$ and attitude of subjects regarding $C A D(p<0.05)$.
\end{abstract}

Keywords: Compliance; therapeutic regimen; CAD; factors influencing compliance.

\section{Introduction}

Coronary artery disease is the most common cause of heart disease and the most important single cause of death in the affluent countries of the world. In the overwhelming majority of cases, the disease of the coronary arteries is due to atherosclerosis. The appropriate management of risk factors in coronary artery disease may prevent, modify, or retard the progression of the disease. The prevention and early treatment of heart disease must involve a multifactorial approach and needs to be ongoing throughout the life span. The person who has modifiable risk factors should be encouraged and motivated to make lifestyle changes to reduce the risk of coronary artery disease. If the person is effectively following the lifestyle modifications like diet, exercise etc and strict adherence to therapeutic regimen can effectively reduce the risk and complications associated with coronary artery disease. It can also help to keep the people apart from surgical modalities like coronary artery bypass graft (CABG) and associated surgical complications.

\section{Need for the Study}

Compliance simply means whether the patient follow the recommendations made by the team of healthcare professionals. These recommendations often include taking medications as well as making lifestyle changes such as stop smoking, eating right and getting the right kind of physical activity in daily life. Worldwide, non-compliance is a major obstacle to the effective delivery of health care. Estimates from the WHO (2003) indicate that only about $50 \%$ of patients with chronic diseases living in developed countries follow treatment recommendations. During the clinical experience, the researcher has come across many patients with coronary artery disease. When the researcher went through such cases it showed that, the common problem faced by all of them was associated with non-compliance with drug regimen. So many previous studies on therapeutic compliance strongly support the importance of carrying out further studies in this aspect.

\section{Statement of the Problem}

An exploratory study on compliance with therapeutic regimen in patients with coronary artery disease attending cardiology outpatient department in a selected tertiary care hospital at Thiruvananthapuram.

\section{Objectives of the Study}

- To assess the level of compliance with therapeutic regimen

- To identify factors contributing to therapeutic compliance of patients with coronary artery disease

- To identify association between therapeutic compliance and selected socio-demographic variables of patients with coronary artery disease.

- To identify the association between therapeutic compliance and selected factors influencing compliance

\section{Operational definition}

\section{Compliance}

In this study, compliance refers to the adherence of patients with coronary artery disease to therapeutic regimen 


\section{International Journal of Science and Research (IJSR) \\ ISSN (Online): 2319-7064 \\ Index Copernicus Value (2013): 6.14 | Impact Factor (2014): 5.611}

prescribed by the cardiologist that will be measured using a compliance questionnaire.

\section{Therapeutic regimen}

In the present study, therapeutic regimen refers to the various aspects of coronary artery disease management such as dietary management, drug therapy, exercises and cessation of social habits such as smoking and alcoholism.

\section{Patient with coronary artery disease}

In this study patient with CAD refers to all clients diagnosed (medical \&surgical) to have coronary artery disease by a cardiologist and is on treatment.

\section{Hypotheses}

$\mathbf{H}_{\mathbf{1}}$ : There is a significant association between compliance with therapeutic regimen and knowledge of subjects regarding coronary artery disease

$\mathbf{H}_{\mathbf{2}}$ : There is a significant association between compliance with therapeutic regimen and attitude of subjects regarding coronary artery disease

$\mathbf{H}_{3}$ : There is a significant association between compliance with therapeutic regimen and selected socio- demographic variables.

\section{Methodology}

Research Approach: In the present study, quantitative approach is used

Research Design: The design selected for the present study is descriptive exploratory research design.

Setting of the Study: The study was conducted at outpatient department of Cardiology, SreeGokulam Medical College Hospital (SGMCH).

Population: In the present study, the population is all patients with coronary artery disease.

\section{Inclusion criteria}

The present study includes patients with

- Coronary Artery Disease

- Attending Cardiac OPD

- Willing to Participate in the Study

\section{Exclusion criteria}

The study excludes patients

- who are included in any other on-going research

- unlikely to visit the institution again for follow-up

- new with coronary artery disease who are under treatment for less than three months

- who are cognitively impaired

Sample: The sample constitutes all patients with coronary artery disease undergoing treatment for three months or more at SreeGokulam Medical College Hospital, Thiruvananthapuram.

Sample size: Sample for the present study consisted 200 patients with coronary artery disease attending the cardiology outpatient department of SGMCH.
Sampling technique: In this study the researcher had used consecutive sampling to select subject who fulfils the criteria for sample selection are chosen to participate in the study.

\section{Tool/Instruments of the study}

In the study the instruments used were socio demographic proforma, questionnaire to assess compliance, knowledge questionnaire and attitude scale used to assess the factors influencing compliance.

\section{Description of tool}

The tool was developed by the investigator and used for the study.

Section A: Socio demographic data

Section B: Questionnaire to assess compliance

Section C: Factors influencing compliance

Section A: Socio demographic data consist of variables such as age, gender, marital status, type of family, educational status, occupation, monthly income, food habit, co morbidities, duration of drug therapy, history of smoking and number of cardiac drugs intake per day.

Section B: Questionnaire to assess compliance which includes food habits, exercise, medication intake, checking of body weight, habit of alcoholism, over the counter medication.

Section C: Factors influencing compliance which includes knowledge questionnaire regarding coronary artery disease and five point attitude scale.

\section{Data Collection Procedure}

The study was conducted to explore the level of compliance of patients with coronary artery disease. 200 patients with coronary artery disease who met the inclusion criteria were identified from the cardiology outpatient department. The investigator introduced himself and explained regarding the study and assured confidentiality of the information provided by the study participants. Informed consent was obtained from each study participants to ensure their willingness to participate in the study. The data was collected using a structured interview schedule from patients with coronary artery disease regarding socio-demographic variables, knowledge of subjects regarding coronary artery disease, attitude of subjects regarding coronary artery disease, financial support, family support and advices from health care professionals related to therapeutic regimen.

\section{Results}

Frequency, distribution and percentage of subjects based on socio demographic variables

- Among the subjects, $37 \%$ belonged to the age group of 50-59 years, $36.5 \%$ subjects belonged to 40-49 years, $17 \%$ subjects belonged to $60-69$ years and only $8 \%$ subjects belonged to 70-79 years.

- More than half of the subjects (58.5\%) were males and $41.5 \%$ subjects were females.

- Most of the $(95 \%)$ of subjects were married and $96.5 \%$ belong to nuclear family 


\section{International Journal of Science and Research (IJSR) \\ ISSN (Online): 2319-7064}

Index Copernicus Value (2013): 6.14 | Impact Factor (2014): 5.611

- Among the subjects majority (66.5\%) had only high school education, $61 \%$ were self-employed/private employed, $18.5 \%$ were unemployed and $10.5 \%$ were retired.

- Majority of subjects (60\%) were having a monthly income between Rs 5001-7500, 16\% have monthly income between Rs 2501-5000, $15.5 \%$ have monthly income between Rs 7501-10000 and only 5.5\% were having an income greater than Rs 10000.

- Most of the subjects $(94.5 \%)$ were non-vegetarian and $(5.5 \%)$ were strict vegetarian.

- Among the subjects more than half (55.5\%) of the subjects had hypertension, $31.5 \%$ had diabetes mellitus and $(3 \%)$ of subjects had other diseases like hyperlipidaemia as co-morbidity.

- Most of the subjects (72.5\%) were receiving drug therapy since 1-3 years of and $15.5 \%$ of subjects were in 3-5 years of drug therapy.

- Majority (69\%) of subjects were non-smokers and $31 \%$ of subjects were smokers.

- More than half $(53.5 \%)$ of the subjects were taking 2 cardiac drugs per day and $42.5 \%$ were taking 3 cardiac drugs per day and $3.5 \%$ were taking more than 3 number of cardiac drugs per day.

Level of compliance with therapeutic regimen among subjects with coronary artery disease.

- $39.5 \%$ of the subjects have poor compliance with therapeutic regimen

- $31.5 \%$ of subjects have average and $29 \%$ have good compliance with their therapeutic regimen.

\section{Level of knowledge of subjects regarding coronary} artery disease

- Majority of subjects (55\%) have average knowledge regarding coronary artery disease.

- $23.5 \%$ of subjects have poor knowledge and only $21.5 \%$ have good knowledge regarding coronary artery disease.

Level of attitude of subjects regarding coronary artery disease

- Majority (60.5\%) have favourable attitude towards coronary artery disease

- $39.5 \%$ of subjects have unfavourable attitude towards coronary artery disease

Financial support, family support and health advices to subjects with coronary artery disease

- Most of the subjects have good financial support (91.5\%) from family for the treatment of CAD.

- More than half of the subjects (74.5\%) got adequate family support from relatives and family members for the management of coronary artery disease

- $47 \%$ received advices from health care professionals.

Association between level of compliance and selected socio demographic variables

- There was no significant association found between therapeutic compliance and other socio demographic variables such as age, sex, educational status, occupation and food habit of subjects.
Association between level of compliance and selected factors influencing compliance

- There was a significant association between level of compliance of patients with coronary artery disease and attitude of subjects regarding CAD $(\mathrm{p}<0.05)$

- There was no association between knowledge and level of compliance of patients with coronary artery disease.

\section{Discussion}

In the present study, it was found that only $21.5 \%$ have good knowledge regarding coronary artery disease. This study is consistent with the study findings of Khadka M et al (2012) which revealed that, among 196 participants, only 22\% had good level of knowledge regarding modifiable risk factors of coronary atherosclerotic heart disease. This study is also consistent with the another study findings of Abhinav $\mathrm{V}$ et al (2013) which showed that among 777 participants, nearly $44 \%$ of participants had poor knowledge and less than $20 \%$ had highly satisfactory knowledge on cardiovascular health.

The findings of the present study are in contrast with the findings of another study conducted by Omar S et al (2009) at All India Institute of Medical Science, New Delhi. It was a study on the knowledge of modifiable risk factors of CASHD conducted among an Indian population. $41 \%$ of the sample surveyed had a good level of knowledge. $68 \%, 72 \%$, $73 \%$ and $57 \%$ of the population identified smoking, obesity, hypertension, and high cholesterol. 30\% identified diabetes mellitus as a modifiable risk factor of CASHD.

In the present study it was found that $55 \%$ have average knowledge about coronary artery disease. This study is supported by the study findings of Namrathaetal (2010) which revealed that $53 \%$ of subjects have average knowledge about coronary artery disease.

In the present study, $60 \%$ of the subjects have favourable attitude and $39.5 \%$ have unfavourable attitude towards coronary artery disease. This is consistent with the study findings of Ranimah Y et al (2012) whose study revealed that, among 448 women participated, the good knowledge, attitude and practice score were $(55.6 \%),(55.1 \%)$ and $(51.1 \%)$ respectively.

This study is in concordance with the study findings of Yadav KD et al (2012) on knowledge and attitude regarding major risk factors of cardiovascular diseases among 15-19 year old students of Kathmandu district. The study revealed that, nearly half $(47.9 \%)$ of the subjects had neutral attitude followed by positive (31.9\%) and one fifth possessed negative attitude. Knowledge versus attitude regarding the major risk factors of cardiovascular diseases was found statistically significant $(\mathrm{p}=0.002)$.

\section{References}

[1] Lewis, Heitkemper, Dirksen, Bucher. Text book of medical surgical nursing.7thed. India: Mosby publications;2007

[2] H.R Gundu .Coronary artery disease.1st ed. India: Jay pee publications;2005

[3] Michael P, Chris L, John S. Medication adherence its Importance in cardiovascular outcomes, J Am Heart

\section{Volume 4 Issue 11, November 2015}




\section{International Journal of Science and Research (IJSR) \\ ISSN (Online): 2319-7064}

Index Copernicus Value (2013): 6.14 | Impact Factor (2014): 5.611

Assoc [Internet].2009[cited 2013 May13].; Available from :http://circ.ahajournals.org/content/119/23/3028

[4] Perlis K. Know your medicine compliance, J PharmacDivisi, ministry of Malaysia [Internet] 2014 [cited 2014 Apr 20].186(7).Available from; http://www.knowyourmedicine.gov.my/index.cfm?\&me nuid $=18 \&$ parentid $=5$

[5] Shanthi M, Pekka P. Global atlas on cardio vascular disease prevention and Control [Internet] 2011 [cited 2013 Apr 19].Available from;http://whqlibdoc.who.int/publications/2011/97892 41564373_eng.pdf

[6] Susan L,Erika S.Cardiac nursing.6th ed. Philadelphia: LippincottPublications; 2010 ;810-901

\section{Author Profile}

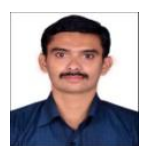

Mr. Jackson John had undergone Bachelor of Science in Nursing from Theophilus college of Nursing, Kottayam, after completion of Bsc Nursing had been worked as a staff nurse at Baby Memorial Hospital, Kozhikodu. Completed Msc (critical care Nursing) from SreeGokulam Nursing college, venjaramoodu, Trivandrum. Now working with Askham Village Community, March, Cambridgeshire, United Kingdom

Mrs.Haseena MSc (N) is currently working as Associate Professor and Head of the department, Medical Surgical Nursing, SreeGokulam Nursing College, Trivandrum. She completed her Bachelors in Nursing from SreeBalaji College of Nursing and received her Masters in Nursing with first rank from Meenakshi College of Nursing, Chennai. She has been a resource person for various national conferences and also has published research papers in national and international journals. 